To cite this article: Odet Moliner, Auxiliadora Sales, Reina Ferrández \& Joan Traver (2011): Inclusive cultures, policies and practices in Spanish compulsory secondary education schools: teachers' perceptions in ordinary and specific teaching contexts, International Journal of Inclusive Education, 15:5, 557-572

\title{
Inclusive cultures, policies and practices in Spanish compulsory secondary education schools: teachers' perceptions in ordinary and specific teaching contexts
}

\author{
Odet Moliner, Auxiliadora Sales, Reina Ferrández and Joan Traver \\ Department of Education, University Jaume I, Castellón, Spain
}

This article presents a study that attempts to inquire into the indicators related with inclusive education by taking into account teachers' responses in the ordinary and specific teaching contexts (experts in special education needs, specialists in therapeutic pedagogy and compensatory education or specific programmes organised to accommodate diversity). We used a Spanish translation of the Index for Inclusion, which has been adapted and divided into three Likert-type scales about inclusive cultures, organisation in the teaching-learning context and inclusive practices. We did a $t$-test to detect any significant differences in teachers' responses in terms of the ordinary or specific teaching contexts in which they work. No significant differences were seen in the items related to cultures and organisation, but we found significant differences in 12 of the 36 items of the inclusive practices scale. Finally, we discuss the role of the processes for innovation and transformation in secondary schools and provide key factors to build an intercultural inclusive school.

Keywords: inclusive education; teacher's perceptions; secondary schools

\section{Introduction}

Teachers' perceptions of good practices or about those that come closer to their conception of inclusive practices vary considerably from some contexts to others and are conditioned by the different meanings of the term 'inclusive education', which has been a matter of great debate worldwide. We consider that inclusive education means education in diversity, which is an ethical and pedagogic option that implies, first, assuming diversity by considering each person as a different individual with his or her own peculiarities and a way of being and living; second, accepting diversity as a value and always from a few shared minimums; third, starting pedagogical strategies that are able to respond to heterogeneous situations and promote the exchange of perspectives as a way of mutual enrichment.

Indeed, international organisations such as UNESCO (2005) or the European Agency for Development in Special Needs Education (2005)1 have elaborated documents that help clarify those practices that may be considered inclusive. By studying the examples of good practices from each country involved in their elaboration, seven common factors were found: cooperative teaching, cooperative learning, cooperative solutions to conflicts, heterogeneous groupings, efficient pedagogic approaches, the classroom reference system and alternative learning strategies. The last two factors seem to be of particular importance at the secondary education stage. 
In Canada, which is likely to be currently the most inclusive country in the world for persons with disabilities (Brodin and Lindstrand 2007, 144) in spite of education policies varying from one province to another, three critical factors that achieve inclusion- based schools and classes have been identified (Porter 1997): first, leadership in the policy, administration and implementation of the inclusive proposal; second, establishing a new role for the special needs' teacher as a resource expert who offers his or her support to the school; and third, strategies for an inclusive class teacher, such as personal development strategies, teams of colleagues to overcome problems and strategies concerning inclusive-related methodologies, for instance, multilevel teaching. In the UK, the works of Booth and Ainscow (1998) are well known. These are research works that compare the conception of and illustrate 'good practices' in eight countries. In this context, an instrument that enables the assessment of the inclusion/ exclusion processes of schools was elaborated from the indicators used to reach a consensus, this being the so-called Index for Inclusion (Booth and Ainscow 2000).

This tool is to help teach teams, families, students and the community to reflect, and its use is linked with the establishment of improvement series for schools. It has been translated into Arabic, Swedish, Hungarian, Chinese, French, German and Spanish. In Spain, the Index for Inclusion has been translated into and adapted to Spanish, and is entitled Guía para la evaluación y mejora de la educación inclusiva (Guide to assess and improve inclusive education) (Sandoval et al. 2002). From this translation, versions are available in Catalan and Basque, and its use is gradually extending (Duran et al. 2005; Huguet 2006). In the former works, we already pointed out how teachers' pedagogic thoughts influence their teaching activities (Traver et al. 2005), and how their beliefs in and perceptions of the diversity of students influence their didactic and organizational proposals (Doménech et al. 2006). Along the same lines, the work that we present intends to inquire into teachers' perceptions of the indicators related to inclusive education in terms of the culture, policies and practices within compulsory secondary education schools in a province of east Spain.

Although certain things have been achieved since school integration began in Spain in 1985, some of them still need to be worked on. The 1990 Organic Act on the General Organisation of the Education System (LOGSE) lays down the integration of special education within the mainstream system and introduces the concept of 'special educational needs'. It establishes that all educational necessities should be attended to within the framework of a comprehensive education system that is open to diversity. This Act also establishes that pupils with special educational needs should attend mainstream establishments and programmes by adapting such programmes to the individual capacities of each pupil. In order to put the principle of equality in the exercise of education rights into practice, the public authorities will carry out compensatory measures with disadvantaged students and provide the necessary resources and support. Nowadays, LOE, the Organic Law of Education 2006, changes the scope and the objectives on special education and introduces the concept of 'specific educational supports needs'. It must be taken into account that education focuses on achieving respect for basic rights and liberties, and equal rights and opportunities between men and women, as well as an equal treatment and nondiscrimination for the disabled.

In the Spanish context, every secondary school of compulsory education plans the development and functioning of the curricular diversity programmes, adapted curriculum groups, compensatory programmes or any 'extraordinary' or 'specific' resource that is generated in a school to attend students with 'specific educational supports needs' within their Attention to 
Diversity Plan. In the Spanish context, there is the possibility of making resources or alternative programmes available to these students outside the ordinary classroom (specific programmes). In this work, we use 'ordinary context' to refer to any educational practice developed in the ordinary classroom. We use 'specific context' to refer to the practices developed in the programmes that allow some students, who participate in an alternative programme, to be relocated to the ordinary classroom, for instance, linguistic programmes for immigrant students, special programmes for learning disabilities or special programmes for disabled children.

\section{Study of teachers perceptions of the inclusive policies, cultures and practices in secondary education schools}

This is an inferential study that attempts to inquire into the indicators related with inclusive education by taking the responses of the ordinary and specific teaching contexts in the participating schools as a reference. When we talk about ordinary teaching staff, we refer to those teaching professionals who teach various theme matters or course subjects as a part of a secondary education syllabus, which are grouped and coordinated from the various teaching departments but are taught in ordinary classrooms. The term specific teaching staff refers to those teaching professionals whose teaching tasks take place in the classrooms where an alternative is provided: experts in special education needs, experts in therapeutic pedagogy and compensatory education, experts in resources or specific programmes organised to accommodate diversity (such as curricular diversity programmes or adapted curriculum groups), or expert teachers in the reception classroom with students who joined later.

\subsection{Objective of the research}

Therefore, the objective of this research may be summarised as the analysis of differences among teachers with regard to indicators of inclusion depending on the context in which they work.

\subsection{Methodology}

The survey we present attempts to analyse the status of the question as far as the opinions and attitudes towards inclusive practices are concerned, and also attempts to go a little further by analysing whether these opinions and attitudes differ depending on the context in which the teacher works.

\subsubsection{Instruments}

We used the Questionnaire about attending diversity in ESO schools [Educació Secundària Obligatòria (ESO), Compulsory Secondary Education] to be completed by the teachers. This questionnaire is a Spanish translation of the Index for Inclusion (Booth and Ainscow 2000), which has been adapted by the University Consortium for Inclusive Education. It includes 63 Likert-type items, which are divided into three groups corresponding to the Index dimensions: (1) 'creating inclusive cultures'; (2) 'organisation in the teaching-learning context'; and (3) 'developing inclusive practices'. The first scale with five scalars consists of 15 items, the second also has five scalars of 12 items, while the third includes 36 items with three response values (2: Yes; 0 : No; and 1: Sometimes). The internal consistency of this instrument proved satisfactory with a Cronbach's $\alpha$ of 0.788 . 


\subsubsection{Sample}

A random selection of 16 secondary schools was done. The aim was to include schools not only in the city centre but also on the coast, inland and to the north and south of the province. Having completed the selection, questionnaires were forwarded to these schools.

The relevant characteristics of the 16 schools taking part in this research were that most of them $(81.3 \%)$ were public and almost all $(93.8 \%)$ had diversity attention programmes in operation, $68.8 \%$ had compensatory education programmes, $75.0 \%$ had curricular diversity programmes and $25.0 \%$ presented other programmes such as adapted curriculum groups. The counsellors and heads of these schools contributed to and helped the questionnaires reach those teachers who wished to respond voluntarily and anonymously. A total of 131 valid questionnaires were collected. The characteristics of the participating teachers can be seen in Table 1, which also provides the descriptive statistics of the sample in terms of the ordinary or specific teaching contexts in which these teachers work.

Other variables defining the sample in terms of their education and experience with regard to diversity attention are listed below:

(1) Most teachers $(74.0 \%)$ have taught students with special educational needs in their classrooms. A high percentage stated they have had students with learning disabilities owing to socio-economic, family or cultural reasons $(75.5 \%)$, followed by intellectual deficiency $(55.1 \%)$ and behavioural disorders $(54.1 \%)$ such as hyperactivity, etc.

(2) More than half, 58.3\%, had received training on attention to diversity, a percentage that slightly increases to $60.3 \%$ in the specific teaching context.

(3) However, only $39.8 \%$ reported having taken part in specific programmes on diversity attention, although half of the teachers working in the specific teaching context stated that they had participated in such programmes $(50.9 \%)$.

Table 1. Characteristics of a teaching sample in terms of the (ordinary or specific) context variable in which teachers work (in percentages).

\begin{tabular}{|l|c|c|c|c|c|c|c|c|c|c|c|c|c|}
\hline & \multicolumn{3}{|c|}{ Age } & \multicolumn{3}{c|}{ Gender } & \multicolumn{3}{c|}{ Years of teaching } & \multicolumn{3}{c|}{ Occup. status } & \multicolumn{3}{c|}{ Qualification } \\
\hline & $<30$ & $31-50$ & $>51$ & $\mathrm{M}$ & $\mathrm{F}$ & $<5$ & $6-20$ & $>21$ & Stable & $\begin{array}{c}\text { Uns- } \\
\text { table }\end{array}$ & $\begin{array}{c}3-\mathrm{yr} \\
\text { degree. }\end{array}$ & $\begin{array}{c}4 / 5-\mathrm{yr} \\
\text { degree }\end{array}$ & Dr. \\
\hline Ord. & 11.3 & 66.2 & 22.5 & 47.9 & 52.1 & 25.0 & 50.0 & 25.0 & 68.1 & 31.8 & 23.6 & 72.2 & 4.2 \\
\hline Spec. & 15.8 & 73.7 & 10.5 & 51.7 & 48.3 & 23.6 & 50.9 & 25.5 & 75.4 & 24.6 & 12.5 & 82.1 & 3.6 \\
\hline Total & $\mathbf{1 3 . 3}$ & $\mathbf{6 9 . 5}$ & $\mathbf{1 7 . 2}$ & $\mathbf{4 9 . 6}$ & $\mathbf{5 0 . 4}$ & $\mathbf{2 4 . 4}$ & $\mathbf{5 0 . 4}$ & $\mathbf{2 5 . 2}$ & $\mathbf{7 1 . 5}$ & $\mathbf{2 8 . 6}$ & $\mathbf{1 8 . 8}$ & $\mathbf{7 6 . 6}$ & $\mathbf{3 . 9}$ \\
\hline
\end{tabular}

\subsubsection{Data processing}

All the data obtained were processed with the SPSS statistics package (version 13.0). The descriptive statistics were obtained, the reliability of the instrument was checked (Cronbach's $\alpha$ ) and $t$-tests were done.

\subsection{Results}

Firstly, we present the descriptive measures to determine the level of responses to the inclusive practice indicators in terms of Dimensions A-C. Secondly, we did a $t$-test to see whether there were significant differences in teachers' responses in terms of the ordinary or specific teaching contexts in which they work. With regard to the descriptive results, Tables 2-4 show the main average scores and dispersions. 
The results of Dimension A, 'Creating inclusive cultures', enable us to describe the participating teachers' perceptions of the culture of their schools in terms of values, attitudes and beliefs. Only scores higher than 3.5 and lower than 2.5 have been taken into account for the description. It is considered that all the students are received in one school (dima1) irrespectively of their characteristics, although there are some students who will never be able to learn (dima8r). Collaboration between teachers and families is good (dima15).

On the other hand, diversity among students is considered as a problem that hinders learning (dim11r). In this sense, few teachers think that the barriers to learn are related to the organisation of the school and the syllabus (dima4). Therefore, a problematic perception of diversity is felt and it centres on the student as if he/she was a problem.

Table 2. Means (from highest to lowest) and standard deviations of the scores obtained from each item in Dimension A.

\begin{tabular}{|l|l|l|l|}
\hline Items & $\mathrm{N}$ & Mean & s.d. \\
\hline dima1 & 129 & $\mathbf{4 . 6 4}$ & .770 \\
\hline dima8r & 131 & $\mathbf{3 . 9 5}$ & 1.189 \\
\hline dima15 & 126 & $\mathbf{3 . 7 1}$ & .956 \\
\hline dima13r & 129 & $\mathbf{3 . 6 4}$ & 1.191 \\
\hline dima11r & 128 & $\mathbf{3 . 5 5}$ & 1.176 \\
\hline dima12 & 128 & 3.48 & 1.087 \\
\hline dima5 & 128 & 3.48 & 1.203 \\
\hline dima14 & 128 & 3.25 & .887 \\
\hline dima10 & 121 & 3.25 & 1.135 \\
\hline dima2 & 121 & 3.21 & 1.168 \\
\hline dima6 & 117 & 3.13 & 1.103 \\
\hline dima7r & 119 & 2.71 & 1.068 \\
\hline dim3r & 128 & 2.68 & 1.086 \\
\hline dima4 & 129 & $\mathbf{2 . 2 1}$ & 1.051 \\
\hline
\end{tabular}

In relation to Dimension B, 'Organisation of the teaching-learning context', the results obtained allow us to approach the school's organisational policy. Only average scores over 3.5 and under 2.5 have been considered for this description. The counselor is considered as a person who favours the reflection about how sporadic actions may initiate improvement processes that affect the school as a whole (dimb17). It is also considered that new teachers are received and informed about the school (dimb16). Schools attempt to improve physical access (dimb26), and their teachers' stable status is one of the factors that allows progress to be made in diversity attention (dimb21).

Furthermore, and only occasionally, having expelled certain students is considered to lower the schools' lack of discipline (dimb18r).

As for Dimension C, 'Developing inclusive practices', the results presented in Table 4 show the mean scores obtained. We must bear in mind those scores higher than 1.5 and those lower than 0.5 to interpret these results. Teachers believe that the students are well aware of not only regulations on classroom behaviour (dimc49) but also the results of assessments that provide teachers with clues as to how they can improve their syllabus (dimc48). In relation to assessments, students frequently review their exams or those of their classmates (dimc29), and teachers believe that this practice favours students' self-learning (dimc46), and that it adapts the contents to students' former knowledge (dimc28); it explains the objectives of the activities 
clearly (dimc40), and also that the various types of activity are done in one same didactic unit (dimc31); it encourages both students' participation in out-of-school activities (dimc62) and the interchange of experiences with classmates for mutual support (dimc59); it teaches students what they can learn from others from different contexts (dimc60); it enables adjustments so that disabled students can participate (dimc34); it uses different groupings in one same didactic unit (dimc42); it encourages students to orally express or write what they have learnt (dimc41); it adapts the methodology to different learning styles (dimc52); and it considers that the support teaching staff has a clear description of their tasks and duties (dimc54).

Table 3. Means and standard deviations (from highest to lowest) of the scores obtained for each item of Dimension B.

\begin{tabular}{|l|l|l|l|}
\hline Items & $\mathrm{N}$ & Mean & s.d. \\
\hline dimb17 & 126 & $\mathbf{4 . 0 6}$ & 1.076 \\
\hline dimb16 & 123 & $\mathbf{3 . 9 3}$ & 1.046 \\
\hline dimb26 & 120 & $\mathbf{3 . 8 3}$ & 1.001 \\
\hline dimb21 & 125 & $\mathbf{3 . 8 0}$ & 1.024 \\
\hline dimb22r & 124 & 3.49 & 1.246 \\
\hline dimb23r & 128 & 3.41 & 1.153 \\
\hline dimb19 & 117 & 3.40 & 1.009 \\
\hline dimb24 & 126 & 3.37 & 1.017 \\
\hline $\operatorname{dimb25r}$ & 128 & 3.35 & 1.194 \\
\hline dimb27 & 99 & 3.32 & .998 \\
\hline dimb20 & 123 & 3.19 & 1.059 \\
\hline dimb18r & 126 & $\mathbf{2 . 5 8}$ & 1.134 \\
\hline
\end{tabular}

On the other hand, the lowest scores of Dimension $\mathrm{C}$ about developing inclusive practices dealt with the amount of materials available that are adapted to disabled students (dimc35), the use of families as support resources in the classroom (dimc56), students themselves as problemsolving sources related to discipline (dimc50) and the educational use of different community professionals such as social workers, judges, police officers, etc. (dimc57).

Table 4. Means and standard deviations (from highest to lowest) of the scores obtained in each item of Dimension C.

\begin{tabular}{|l|l|l|l|}
\hline Items & $\mathrm{N}$ & Mean & s.d. \\
\hline dimc49 & 129 & $\mathbf{1 . 9 7}$ & .214 \\
\hline dimc48 & 128 & $\mathbf{1 . 7 8}$ & .485 \\
\hline dimc29 & 125 & $\mathbf{1 . 7 8}$ & .522 \\
\hline dimc46 & 128 & $\mathbf{1 . 7 7}$ & .478 \\
\hline dimc28 & 129 & $\mathbf{1 . 7 6}$ & .480 \\
\hline dimc40 & 129 & $\mathbf{1 . 7 5}$ & .485 \\
\hline dimc31 & 128 & $\mathbf{1 . 7 1}$ & .504 \\
\hline dimc62 & 127 & $\mathbf{1 . 7 1}$ & .565 \\
\hline dimc59 & 129 & $\mathbf{1 . 7 1}$ & .551 \\
\hline dimc60 & 127 & $\mathbf{1 . 6 2}$ & .603 \\
\hline dimc34 & 117 & $\mathbf{1 . 5 8}$ & .698 \\
\hline dimc42 & 128 & $\mathbf{1 . 5 7}$ & .611 \\
\hline dimc41 & 127 & $\mathbf{1 . 5 4}$ & .652 \\
\hline
\end{tabular}




\begin{tabular}{|l|l|l|l|}
\hline dimc52 & 129 & $\mathbf{1 . 5 3}$ & .587 \\
\hline dimc54 & 109 & $\mathbf{1 . 5 2}$ & .675 \\
\hline dimc37r & 128 & 1.45 & .761 \\
\hline dimc53 & 127 & 1.43 & .674 \\
\hline dimc55 & 127 & 1.43 & .685 \\
\hline dimc47 & 128 & 1.40 & .703 \\
\hline dimc30 & 125 & 1.38 & .715 \\
\hline dimc61 & 122 & 1.35 & .738 \\
\hline dimc58 & 128 & 1.34 & .681 \\
\hline dimc44 & 126 & 1.17 & .728 \\
\hline dimc63 & 128 & 1.14 & .811 \\
\hline dimc51 & 123 & 1.14 & .852 \\
\hline dimc39 & 98 & 1.10 & .879 \\
\hline dimc36 & 127 & 1.07 & .828 \\
\hline dimc43 & 126 & 1.04 & .731 \\
\hline dimc38 & 127 & .98 & .740 \\
\hline dimc33r & 125 & .86 & .901 \\
\hline dimc32 & 125 & .83 & .922 \\
\hline dimc45 & 124 & .82 & .837 \\
\hline dimc57 & 127 & .57 & .730 \\
\hline dimc50 & 126 & .53 & .561 \\
\hline dimc56 & 126 & .48 & .666 \\
\hline dimc35 & 118 & .44 & .768 \\
\hline
\end{tabular}

With regard to the second step, we did a $t$-test to see whether there were significant differences in teachers' responses in terms of the ordinary or specific teaching contexts in which they work. The results show major differences only in Dimension C, no differences in Dimension B and differences for only one item in Dimension A: dima15 $(p<0.01)$ relates to the degree of collaboration between teachers and families. In this case, ordinary teaching staff obtained higher scores.

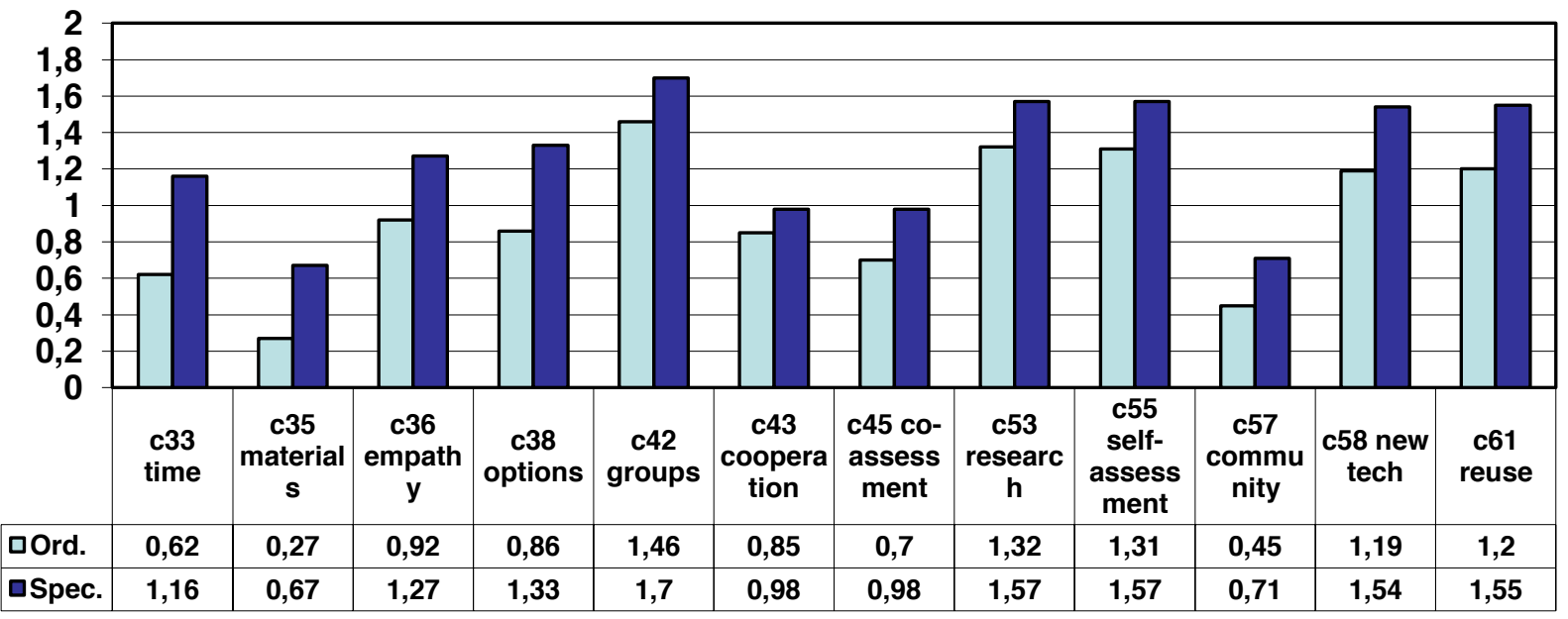

Graph 1. Results per item which proved significant for secondary education teachers in terms of the ordinary or specific context. 
The differences found in Dimension C affect 12 of the 36 items, and the teachers who do their work in specific contexts also obtained higher scores (see Figure 1). These items relate to dimc35: adapted materials ( $p<0.01)$; dimc36: empathy $(p<0.05)$; dimc38: optional subjects $(p$ $<0.05)$; dimc42: various groupings $(p<0.05)$; dimc43: cooperative learning $(p<0.01)$; dimc45: co-assessment $(p<0.05)$; dimc53: research works $(p<0.05)$; dimc55: self-assessment $(p<0.05)$; dimc57: community professionals $(p<0.05)$; dimc58: new technologies $(p<0.01)$; dimc61: reusable resources $(p<0.01)$; and dimc33r: different time $(p<0.01)$.

\section{Discussion of the results}

The results of Dimension A, 'Creating inclusive cultures', allow the participating teachers' perceptions to be described in relation to the culture at the school where they work. Once again, the results reveal that the ESO teachers' beliefs still focus on the traditional special needs' education models, which place the origin or cause of any malfunction of the didactic process on the students themselves, as they consider that 'some students will never be able to learn' and that 'diversity is a problem which hinders learning'. This demonstrates that teachers still defend the classical conceptions, the ideologies that place the blame on students (or on their social and family contexts) or on their academic performance, which lead them to feel frustrated and to their actions losing effectiveness (Rue 1999). This would make finding one's personal autonomy difficult in the face of complex situations with changes, not only in procedures but also in those aspects that relate more to creating a school culture, just as Elliot (1993) indicated, aspects such as personal character or the attitudes of those involved. Therefore, one of the main challenges for teachers teaching ESO will be to free themselves of the beliefs and the values that are typical of a culture that needs amending.

In this sense, the constructivist's perspective stresses teachers' capacity to govern their own actions from personal reflection, attitudes and understanding, where shared reflection and deliberation among equals are the central points that go beyond any training of techniques that teachers can receive. This requires a change of perspective in initial and permanent training that links professional development with organizational development.

From both the professional approach and the critical intellectual, reflective processes are extending among teachers to not only touch on meditation about practice but to also reflect on institutional structures and their effects on the way of analyzing and thinking about the teaching practice itself, and also about the social and political meanings that these structures fulfil. This critical reflection has an essentially emancipated character, that is it must allow for transformation and the critical visions of the unquestioned proposals and habits, traditions and customs, and of the forms that domination and coercion take, which such practices entail, and which are, more often than not, sustained through inertia or self-delusion. This process also involves the search for new possibilities in life that prove to be more rational, fairer and more satisfactory (Carr and Kemmis 1988). In short, teachers' professional development education claims a theoretical and practical model that allows one to become qualified to know how to plan, act and reflect on one's own practice. At the same time, this model helps to develop critical analyses of the tensions and contradictions between social and political ideology in terms of attention to diversity, and the school and social perspective discriminating practice against different people. So, the social, cultural and critical perspective must go hand in hand with an inclusive pedagogic approach, which complements this vision of diversity (Valenzuela, Connery, and Musanti 2000). In the face of category-like and homogenising views, the most recent education trends contemplate teachers' all-inclusive education view that centres more on 
specific institutional contexts and cultures that come, therefore, closer to schoolcentred training, action research, institutional analysis or organisational development. Once again, these approaches bring us nearer to the practice-reflexive professional whom we mentioned earlier, and to the school being a place where problems are solved and where work strategies are based on professional cooperation and collaboration (Alonso and Rodríguez 2004; Duran and Miquel 2004; Parrilla 2004), on classroom management regarding conflicts (Hasbrouck 1997; Morgan et al. 1994; Pugach and Johnson 1995), and on training among teachers that may encourage positive attitudes towards inclusion (Downing, Morrison, and Berecin-Rascon 1996), facilitate interactions in classrooms, and may adapt teaching materials spontaneously, and the social roles and processes among students (Kohler, Ezell, and Paluselli 1999). All this has to be framed in research action processes, which allow one to reflect on a personal teaching model, a model that defines one's specific practice that is shaped by the influence of one's academic past as a student, by one's professional past as a teacher and by one's adaptation to the institutional and social context (Ainscow et al. 2004).

In relation to Dimension B about inclusive policies, the results obtained show that the psychopedagogue figure is highly considered, and that this figure favours reflection about sporadic actions that may initiate improvement processes for the school as a whole. Certainly, psychopedagogues are quite capable of continuously analyzing the institution where they work, which allows a better understanding of educational organisations. What is more, they participate and manage a whole range of elements and possess considerable knowledge of the relationships among members by being immersed in the organisational process, which could well be a good indicator of the organisation status. This situation allows psycho-pedagogues to approach specific realities (for instance, classroom practices) from a micro- and mesosystemic perspective, which may bear witness to the existing conflicts and contradictions between the reality of the school and the ideology or regulations that the school's documents include: the school's education project, regulations on order and operation, the tutorial action plan, the diversity attention scheme, among others. The psycho-pedagogue figure may act as a revitalising element to innovate and implement good practice strategies. Indeed, the psychopedagogues' more global vision of the curricular and organisational aspects for the school and the classroom facilitates their understanding of certain routines and inertia that those who are directly involved in the teaching- learning process (teachers and students) cannot separate and assert so easily.

In relation to the stability of the school's teaching staff being one of the factors that permits the development of education of diversity to progress, it is true that a stable teaching staff may contribute to decision-making and to set up projects as long-term practices, which is especially true of the institutionalisation of the school's projects or programmes. Nevertheless, a high percentage of stability may be a factor that favours reluctance against undertaking innovations and new experiences. In our mind, although a stable teaching staff does not seem to be per se a guarantee for innovation and change towards inclusion, we consider it to be a requirement to move forward in this direction. Evidently, the staff who possess certain continuity and stability may consider mid- to long-term projects as they respond to the initial commitment of the majority of the staff team. So, an intercultural inclusive leadership is needed, one that mobilises and harmonises the various resources of the dimensions in which the community participates (personal ideology, school and professional culture, educational community, education system) for the purpose of developing a transformation action to build an intercultural inclusive school (Essomba 2006, 124). This democratic and qualified leadership is what guides a change towards management models, which match those inclusive practices that accommodate diversity. According to Riel (2000), school leaders need to cover three broad tasks: understanding the 
meanings about diversity; promoting inclusive practices; and building connections between schools and communities. The administrators' role is important but, according to Ainscow (2005), from a transformational perspective on leadership, schools need to empower others to bring about a change, particularly in relation to ways to promote professional development for teachers in supporting teachers and schools to move towards inclusion and interculturality.

As for Dimension $\mathrm{C}$ about inclusive practices, teachers believe that students are well aware of the regulations on classroom behaviour (dimc49). This is important, as asserting regulations is the first step to them being fulfilled. Another different matter is the process by which these regulations have been established. Apparently, teachers are willing to use strategies that favour diversity attention.

Among them, Pujolàs (2003) considers those strategies that regulate learning and those that encourage students' autonomy.

Contemplating the results of the assessments as 'clues' to improve their syllabus (dimc48) is a sign that teachers consider an assessment to be more than a mere evaluation of students, and it becomes an element to be able to reflect on their specific teaching proposal within their syllabus that has a clear repercussion on it (Santos Guerra 2003). Moreover, the fact that students frequently review their exams or those of their classmates (dimc29) indicates that the assessment is a conception of the educational nature, which may provide a way to regulation processes among teachers (through their teaching proposal) and to self-regulation processes among students (learning from mistakes and anticipating difficulties). Another practice that teachers frequently undertake is to explain the objectives of activities (dimc40) that improve the regulation of learning (Jorba and Caselles 1997).

Teachers appear to be quite optimistic about the aspects related to the didactic methodology, such as adapting the contents of students' former knowledge (dimc28) that favours meaningful learning, making adjustments for disabled students to participate (dimc34), diversifying teachers' proposal, adapting the methodology to the various learning styles (dimc52) and doing several kinds of activities within the same didactic unit (dimc31).

As for the interactions that are encouraged among students, those items about the use of several kinds of grouping across the didactic unit are highlighted: teach students what they may learn from others who come from other contexts (dimc60), and encourage students to participate in out-of-school activities (dimc62).

Teachers' perceptions of the support they receive refer to an interchange of experiences with colleagues as a mutual support (dimc59), and they consider that support teachers are able to clearly describe their duties and tasks (dimc54).

On the other hand, the least frequent practices referred to are using the school's 'external' resources such as families (dimc56) and different community professionals such as social workers, judges, police officers, etc. (dimc57). Such practices are typical in learning communities (Alcalde 2006; Elboj et al. 2002; Flecha and Tortajada 1999; Jaussi 2002) and centre on educational experiences that are shaped by participation and by the educational community's combined action (students, teachers, families, and social and community agents).

Another of the least frequent practices is that which involves the students themselves to solve problems of discipline (dimc50). In an attempt to solve the conflicts emerging among students, dialogue is the basis of the models of school mediation and assistance among peers. Informal mediation consists of an assistance system among peers and is an efficient means to improve the well-being and coexistence at the school and to reduce the number of conflicts among students. The results of the $t$-test done on the means show that significant differences were seen only in one item in Dimensions A and B. This indicates that the context in which the teaching activity takes place apparently does not influence teachers' perceptions of the values that shape cultures 
in schools, the organisational cultures or the micropolicy of the school as an organisation. The only exception is item 15 of Dimension A, which deals with the perception of a greater collaboration among the ordinary teaching staff and families, and the specific teaching staff's collaboration being less perceived. The second case may be due to these teachers having greater demands when the conditions of the context and the situation are more difficult and extreme. So, their expectations or demands concerning collaboration may not be fulfilled.

Nevertheless, some significant differences were found in the development of inclusive practices in favour of the specific teaching context. The professionals who teach in specific teaching contexts actually encourage students to make a different timeavailable to do activities more than those in the ordinary teaching context. In other words, adapting to different paces of work and having more adapted materials is logical because it is this specific context that is normally in charge of disabled students, students who do not master the native language or students who need to bridge a larger curricular gap. That is to say, all those aspects that are removed from what is considered the 'norm'. Therefore, they are said to be in contact with, or can rely on, the collaboration of other community professionals (therapists, social workers, interpreters, mediators, etc.) who support these teachers' educational action. The specific teaching context also encourages empathy through games and simulations, and also allows to opt out of several activities, includes new technologies and uses reusable resources to a greater extent than the ordinary teaching context. All this favours the meaningfulness of learning practices in an attempt to come closer to one's interests and, above all, they are the strategies that encourage active participation with students as well as their involvement in self-learning. All this is completed by including other strategies, such as cooperative learning, research works and diversification of groupings, which influence the type of interactions that take place in the classroom, thus creating an environment of acceptance, assistance and shared knowledge (Wells 2001). Furthermore, this leads to the use of co-assessment and self-assessment, which enables students to self-regulate their own learning.

If we consider that 12 of the 36 items show a significant difference in favour of the specific teaching context, we could conclude that these teachers who work in contexts (classrooms, schemes) designed for students with special education needs are more sensitive to the diversity that they manage on a daily basis and are, therefore, more aware of and willing to use pedagogic strategies of a more inclusive nature, just as the results of this study have shown. In this sense, we did not find a consensus about such differences in the literature. However, one clear idea that came over was the fact that doing good practices or inclusive practices in separate contexts brings about a contradictory idea. How can practices be inclusive if they deal with students in a segregated context? They are indeed good practices (efficient for students' characteristics), but the academic organisation is not inclusive. So, we return to the matter of whether the teachers in the specific teaching context could do their work well in a classroom of the ordinary context along with ordinary teaching staff. This matter has been solved in countries like Canada, where teachers' special teaching role has been redefined, and they have become Methods and Resources Teachers (Porter 1991) who collaborate with teachers in ordinary classrooms to counsel, help and encourage them in their educational task.

However, our results and the international analysis and critique of policy for inclusion that have been made in the UK, or even in Sweden, suggest that far from ensuring full participation as a right, the policy for inclusion can be seen to have done little to increase genuine access to the mainstream for children with special educational needs and may well have even increased exclusionary practices therein (Brodin and Lindstrand 2007; Lloyd 2006, 221). These policies seem to be more concerned with remedial, compensatory, individualistic approaches (integration model) that contradict the inclusion model as an entitlement to full participation and 
equal educational opportunity (Benjamin 2002). The goal is not to give special compensation until children achieve equality but to denormalise the way institutions formulate their rules by revealing the plural circumstances and needs that exist (Young 1990, 140). Even Barton (1995) points out the notion that this so-called special expertise is a myth perpetuated by those with a vested interest in the continuance of the segregation of children with special educational needs in order to preserve and safeguard their own positions and professional status. A first step towards a school for all must be to stop talking about normality and deviation and to highlight variation and differences as being positive and useful (Brodin and Lingstrand 2007, 143).

Finally, we wish to highlight the role of the processes for innovation and transformation that take place in schools (of their cultures, policies and practices), which are a guide towards inclusion becoming a kind of diversity attention philosophy in which the teaching staff become more optimistic and encouraged as a reflective practice (Schön 1987) and become involved in the search for alternatives ranging from collaborative inquiry to professional development.

\section{Conclusion}

By the way of conclusion, we wish to point out two lines in which the future research continues to progress. The first is the detection of the facilitator variables that may act as levers in promoting inclusion in the schools themselves. The works of Rousseau and Belanger (2004) point out the essential conditions that facilitate more inclusive proposals being developed, such as developing a common philosophy and a strategic implementation plan, assuming leadership, promotion and accommodating diversity in the classroom, organising a good support system in the school with internal and external help, being flexible, adopting efficient proposals, celebrating successes and being open to the processes of change. The works of Belanger (2006) establish five successfulfactors that favour inclusion: collaboration (with parents in the classroom and with the teaching team), achieving agreed support among the professionals involved in change, the leadership of schools' heads, scheduling changes, and adjustments in accordance with the professionals' needs, attitudes and values. All these factors essentially depend on teachers' attitudes and education, and this opens a way to precisely the environment of intervention and pedagogic implications that we have been looking at.

The second line in which we should continue to progress is that of promoting more inclusive policies and practices that are incompatible with the exclusive educational processes, and that of questioning and inquiring into the results of segregating education, and of analysing and denouncing educational exclusion processes that take place in schools either overtly or covertly.

\section{Note}

1. The documents that form the bases of this report may be consulted in the 'Inclusive Education and Classroom Practice' section of the Agency's web page at www.europeanagency. org, where the following documents may be found: (1) the international literature review on classroom practices: inclusive education and effective classroom practice in secondary schools (2004); (2) reports on exchanges in five countries; and (3) reports of cases from 14 participating countries. All the project information related to primary education is also available.

\section{Notes on contributors}

Odet Moliner is professor Dr and is currently a tenured lecturer in the Department of Education, Faculty of Humanities and Social Sciences, University Jaume I in Castellón (Spain). She is an expert in the field of special education and her main research interest is the inclusive education.

Auxiliadora Sales is a tenured lecturer at the Department of Education, University Jaume I in 
Castellón (Spain). She has taken part in diverse research projects on attitudes, values and intercultural education.

Reina Ferrández is professor Dr in the Department of Education, University Jaume I of Castellón (Spain). She is an expert in the field of quality and education assessment as well as on education programmes.

Joan Traver is professor Dr in the Department of Education, University Jaume I of Castellón (Spain). He has published extensively on cooperative learning, training in attitudes and values and intercultural education programmes.

\section{References}

Ainscow, M. 2005. The next big challenge: Inclusive school improvement. Keynote presentation at the conference of school effectiveness and improvement, January 2-5, in Barcelona, Spain.

Ainscow, M., A. Howes, P. Farrell, and J. Frankham. 2004. Investigación-acción. Una propuesta para el desarrollo de prácticas inclusivas [Action research. Developing inclusive practices]. Cuadernos de Pedagogía 311: 54-9.

Alcalde, A.I. 2006. Transformando la Escuela. Las comunidades de aprendizaje [Transforming Schools. Learning communities]. Barcelona: Graó.

Alonso, P., and P. Rodríguez. 2004. Dos tutores en el aula [Two teachers in the classroom]. Cuadernos de Pedagogía 311: 70-2.

Barton, L. 1995. Segregated special education: Some critical observations. In Researching disabling barriers, ed. G. Zarb, 27-37. London: Policy Studies Institute.

Belanger, S. 2006. Conditions favorisant l'inclusion scolaire: Attitudes des enseignantes du primaire [Conditions for inclusive schools: Teacher's attitudes]. In Transformation des pratiques éducatives: La recherche sur l'inclusion scolaire, ed. C. Dans, C. Dionne and N. Rousseau, 63-88. Québec: Presse de l'Université du Québec.

Benjamin, S. 2002. The micropolitics of inclusive education. Buckingham: Open University Press.

Booth, T., and M. Ainscow, eds. 1998. From them to us: An international study of inclusion in education. London: Routledge.

Booth, T., and M. Ainscow. 2000. The Index for Inclusion. Bristol: Centre for Studies on Inclusive Education.

Brodin, J., and P. Lindstrand. 2007. Perspective of a school for all. International Journal of Inclusive Education 11, no. 2: 133-45.

Carr, W., and S. Kemmis. 1988. Teoría crítica de la enseñanza. La investigación-acción en la formación del profesorado [Becoming critical: Knowing through action research]. Barcelona: Martínez Roca.

Doménech, F., J. Traver, O. Moliner., and A. Sales. 2006. Análisis de las variables mediadoras entre las concepciones educativas del profesor de secundaria y su conducta docente [Analysis of the variables among the educational secondary schools teachers conceptions and theirs educational practice]. Revista de Educación 340: 19-30.

Downing, J.E., A.P. Morrison, and M.A. Berecin-Rascon. 1996. Including elementary school students with autism and intellectual impairments in their typical classrooms: Process and outcomes. Developmental Disabilities Bulletin 24: 20-45.

Duran, D., G. Echeita, C. Giné, E. Miquel, C. Ruiz, and M. Sandoval. 2005. Primeras experiencias de uso de la Guía para la evaluación y mejora de la educación inclusiva (Index for 
inclusion) en el estado español [The first experiences of use of the Guide for evaluation and improvement inclusive education (Index for Inclusion) in the Spanish context]. REICERevista Electrónica Iberoamericana sobre Calidad, Eficacia y cambio en Educación 3, no. 1: 464-7.

Duran, D., and E. Miquel. 2004. Cooperar para enseñar y aprender [Cooperative learning for teaching and learning]. Cuadernos de Pedagogía 311: 73-6.

Elboj, C., I. Puigdellivol, M. Soler, and R. Valls. 2002. Comunidades de aprendizaje: Transformar la educación [Learning communities: Transforming education]. Barcelona: Graó. Elliot, J. 1993. La investigación-acción en la educación [Action-research in education]. Madrid: Narcea.

Essomba, M.A. 2006. Liderar escuelas interculturales e inclusivas. Equipos directivos y profesorado ante la diversidad cultural y la inmigración [Leadership in intercultural and inclusive schools. Management teams and teachers face of cultural diversity and immigration]. Barcelona: Graó

Flecha, R., and I. Tortajada. 1999. Retos y salidas educativas en la entrada de siglo [Challenges and educational success in the next century]. In La educación en el siglo XXI. Los retos del futuro inmediato, ed. F. Imbernon, 13-26. Barcelona: Graó.

Hasbrouck, J.E. 1997. Mediated peer coaching for training preservice teachers. The Journal of Special Education 31, no. 2: 251-71.

Huguet, T. 2006. Aprender juntos en el aula. Una propuesta inclusiva [Learning together in the classroom. An inclusive perspective]. Barcelona: Graó.

Jaussi, M.L., ed. 2002. Comunidades de aprendizaje en Euskadi: Una respuesta educativa en la sociedad de la información para todos y todas [Learning communities in Basque Country:

An educational response in the information society for all]. Vitoria (Gasteiz): Servicio Central de Publicaciones del Gobierno Vasco.

Jorba, J., and E. Casellas. 1997. La regulación y la autorregulación de los aprendizajes [Regulation and self regulation of learning]. Madrid: Síntesis Ediciones.

Kohler, F.W., H.K. Ezell, and M. Paluselli. 1999. Promoting changes in teacher's conduct of student pair activities: An examination of reciprocal peer coaching. The Journal of Special Education 33, no. 3: 154-65.

Lloyd, C. 2006. Removing barriers to achievement: A strategy for inclusion or for exclusion? International Journal of Inclusive Education 12, no. 2: 221-36.

Morgan, R.L., R. Menlove, C.L. Salzberg, and P. Hudson. 1994. Effects of peer coaching on the acquisition of direct instruction skills by low-performing preservice teachers. The Journal of Special Education 28, no. 1: 59-76.

Parrilla, A. 2004. Grupos de apoyo entre docentes [Teachers support teams]. Cuadernos de Pedagogía 311: 66-9.

Porter, G.L. 1991. The methods \& resource teacher: A collaborative consultant model. In Changing Canadian schools: Perspectives on disability and inclusion, ed. G. Porter and D. Richler, 107-54. Toronto: The G. Allen Roeher Institute.

Porter, G.L. 1997. Critical elements for inclusive schools. In Inclusive education. A global agenda, ed. S.J. Pij1, C.J.W. Meijer, and S. Hegerty, 68-81. London: Routledge.

Pugach, M., and L.J. Johnson. 1995. Unlocking expertise among classroom teachers through structured dialogue: Extending research on peer collaboration. Exceptional Children 62, no. 2 : $101-10$.

Pujolàs, P. 2003. Aprendre junts alumnes diferents. Els equips d'aprenentatge cooperatiu a I'aula [Learning togethers. Cooperative teams in the classroom]. Barcelona: Eumo. 
Riel, C.J. 2000. The principal's role in creating inclusive schools for diverse students: A review of normative, empirical, and critical literature on the practice of educational administration. Review of Educational Research 70, no. 2: 55-81.

Rousseau, N., and S. Belanger. 2004. La pedagogie de l'inclusion scolaire [Pedagogy of inclusion]. Québec: Presses de l'Université du Québec.

Rue, J. 1999. La autoevaluación de los equipos docentes, una estrategia de mejora cualitativa de la escuela [Self-evaluation of teacher's teams, a qualitative strategy for improving schools]. Educar 24: 71-8.

Sandoval, M., M.L. Lòpez, E. Miquel, D. Duran, C. Giné, and G. Echeita. 2002. Index for inclusion. Una guía para la evaluación y mejora de la educación inclusiva [Index for inclusion. A guide for evaluation and improvement the inclusive education]. Contextos educativos 5: 22738.

Santos Guerra, M.A. 2003. Una flecha en la diana [An arrow in the reveille]. Madrid: Narcea. Schön, D. 1987. Educating the reflective practitioner. San Francisco, CA: Jossey-Bass. Traver, J., A. Sales, F. Doménech, and O. Moliner. 2005. Caracterización de las perspectivas docentes del profesorado de secundaria a partir del análisis de las variables educativas relacionadas con la acción y el pensamiento docente [Educational perspectives in secondary school teachers. Analysis of the educational variables related to the practice and teachers thinking]. Revista Iberoamericana de Educación (OIE) 8, no. 36: 1-18.

UNESCO. 2005. Guidelines for inclusion: Ensuring access to education for all. Paris: UNESCO.

Valenzuela, J.S., M.C. Connery, and S.I. Musanti. 2000. The theoretical foundations of professional development in special education. Is sociocultural theory enough? Remedial and Special Education 21, no. 2: 111-20.

Wells, G. 2001. Indagación Dialógica: Hacia una teoría y práctica socioculturales de la educación [Dialogical research: Towards a sociocultural theory and practice]. Barcelona: Paidós.

Young, I. 1990. Polity and group difference: A critique of the ideal universal citizenship. In Feminism and political theory, ed. C. Sunstein, 156-91. Chicago, IL: University of Chicago Press. 